\title{
Genetic determination of the ovarian reserve: a literature review
}

\author{
Aleksandra V. Moiseeva', Varvara A. Kudryavtseva', Vladimir N. Nikolenko ${ }^{1,2}$, Marine M. Gevorgyan², \\ Ara L. Unanyan', Anastassia A. Bakhmet ${ }^{1}$ and Mikhail Y. Sinelnikov ${ }^{1,4^{*}}$
}

\begin{abstract}
The ovarian reserve is one of the most important indicators of female fertility. It allows for the evaluation of the number of viable oocytes. This parameter is actively used in pregnancy planning and in assisted reproductive technology application, as it determines chances of successful fertilization and healthy pregnancy. Due to increased attention towards diagnostic tests evaluating the ovarian reserve, there has been a growing interest in factors that influence the state of the ovarian reserve. True reasons for pathological changes in the ovarian reserve and volume have not yet been explored in depth, and current diagnostic screening methods often fall short in efficacy. In the following review we analyze existing data relating to the study of the ovarian reserve through genetic testing, determining specific characteristics of the ovarian reserve through genetic profiling. We explore existing studies dedicated to finding specific genetic targets influencing the state of the ovarian reserve.
\end{abstract}

\section{Introduction}

"Ovarian reserve" is a term that is used to describe the remaining capacity of oocytes in the ovary. With age, the ovarian reserve tends to naturally diminish and normally does not present with pathological changes. Environmental impact, physiological, hormonal, iatrogenic and other factors determine the state of the ovarian reserve. Recently, genetic defects have been directly associated with a significant reduction in the ovarian reserve [1]. In cases of infertility, it is now recommended to perform genetic screening $[2,3]$ in order to assess the extent and management possibilities of existing defects.

Genetic profiles FMR1, EIF4ENIF1, BRCA1/2, H19, HMGB2, ADR- $\alpha 1,2$, ADR- $\beta 2$, NR5A1, ATG7, ATG9A, KHDRBS1, FIGLA, 22q11.2, SPO11, HFM1, GDF9, TP53 have been shown to play a key role in ovarian reserve determination $[4,5]$. Presently, studies have established several important factors that influence the basal ovarian volume and appropriate ovarian response after

\footnotetext{
*Correspondence: Mikhail.y.sinelnikov@gmail.com

1 Sechenov University, Mohovaya 11c10, Moscow, Russian Federation

Full list of author information is available at the end of the article
}

ovarian hyperstimulation during in-vitro fertilization (IVF) treatment. However, many genetically determined characteristics are not sufficiently explored and require further evaluation. In this review we aim to define specific genetic profiles and factors that predispose to early decline of the ovarian reserve.

\section{Materials and methods}

The PubMed, Scopus, Web of Science and eLibrary databases were searched using the following key words and their combination: "ovarian reserve", "ovarian reserve AND genetics", "ovarian reserve AND gen", "ovarian reserve AND genetic", "ovarian reserve AND epigenetic NOT cancer", "ovarian reserve AND genetic screening" and "diminished ovarian reserve". Original studies were included in this review. Meta-analyses and systematic reviews were screened for references applicable to our search criteria.

\section{Results}

Low ovarian reserve is an increasing social problem, as many women are at high risk for early decline of the ovarian reserve. A low reserve is one of the leading causes of

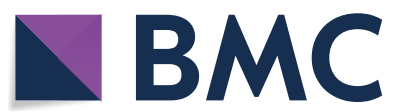

(c) The Author(s) 2021. Open Access This article is licensed under a Creative Commons Attribution 4.0 International License, which permits use, sharing, adaptation, distribution and reproduction in any medium or format, as long as you give appropriate credit to the original author(s) and the source, provide a link to the Creative Commons licence, and indicate if changes were made. The images or other third party material in this article are included in the article's Creative Commons licence, unless indicated otherwise in a credit line to the material. If material is not included in the article's Creative Commons licence and your intended use is not permitted by statutory regulation or exceeds the permitted use, you will need to obtain permission directly from the copyright holder. To view a copy of this licence, visit http://creativecommons.org/licenses/by/4.0/. The Creative Commons Public Domain Dedication waiver (http://creativeco mmons.org/publicdomain/zero/1.0/) applies to the data made available in this article, unless otherwise stated in a credit line to the data. 
female infertility and up to $26 \%$ of women who are undergoing fertility treatment with assisted reproductive technology (ART) have a diminished ovarian reserve (DOR) [6]. Infertility, in turn, leads to various psychological and physical disorders [7]. Diagnostic evaluation of the etiology of ovarian decline is complex, and is aimed at finding individual factors, including genetic and epigenetic, that may have caused early DOR. Besides genetic factors, autoimmune, gynecological, systemic diseases, iatrogenic manipulations (surgery), chemotherapy and environmental impact have been shown to play a significant role in reduced ovarian reserve (Fig. 1) [5]. These factors must be taken into account when using assisted reproductive technologies during in-vitro fertilization.

Current data is unanimous that polycystic ovary syndrome (PCOS) is characterized by an increase in the level of sex hormones. This underlined the importance of dose reduction of administered gonadotropins in order to avoid ovarian hyperstimulation [8]. In obese patients, studies show that more gonadotropic hormones stimulation is required to achieve a sustainable therapeutic effect [9]. In addition to changing the dosage of drugs, for various conditions the approach to the IVF procedure can be adjusted. For example, research shows the efficacy of myo-inositol (MI) and D-chiro-inositol (DCI) (insulinsensitizing agents) in polycystic ovary syndrome [10]. In the case of endometriosis, it is recommended to use IVF as a secondary treatment for women who cannot achieve pregnancy following laparoscopic surgery for up to 12 months [11].

In this review, we delineate several categories of genetic factors according to their influence on the ovarian reserve (OR).

\section{Fragile X Mental Retardation Genes (FMR)}

Fragile X Mental Retardation Genes (FMR) are a family of regulator genes located in the $\mathrm{X}$ chromosome. The Fragile X Mental Retardation 1 (FMR1) gene is commonly associated with neuropsychiatric disorders, but it has been shown to play a role in other pathologies as well. Apart from classical FMR1 disorder symptoms (tremor and ataxia), ovarian dysfunction is also common [12]. FMR1 mutations provoke different pathological changes along with the decline of the ovarian reserve.

The FMR1 gene contains a 5'-UTR triplet repeat (GGG) region, the length of which varies individually. It has been shown that FMR1 gene expression depends on the length and number of these triplet repeats [13]. Four

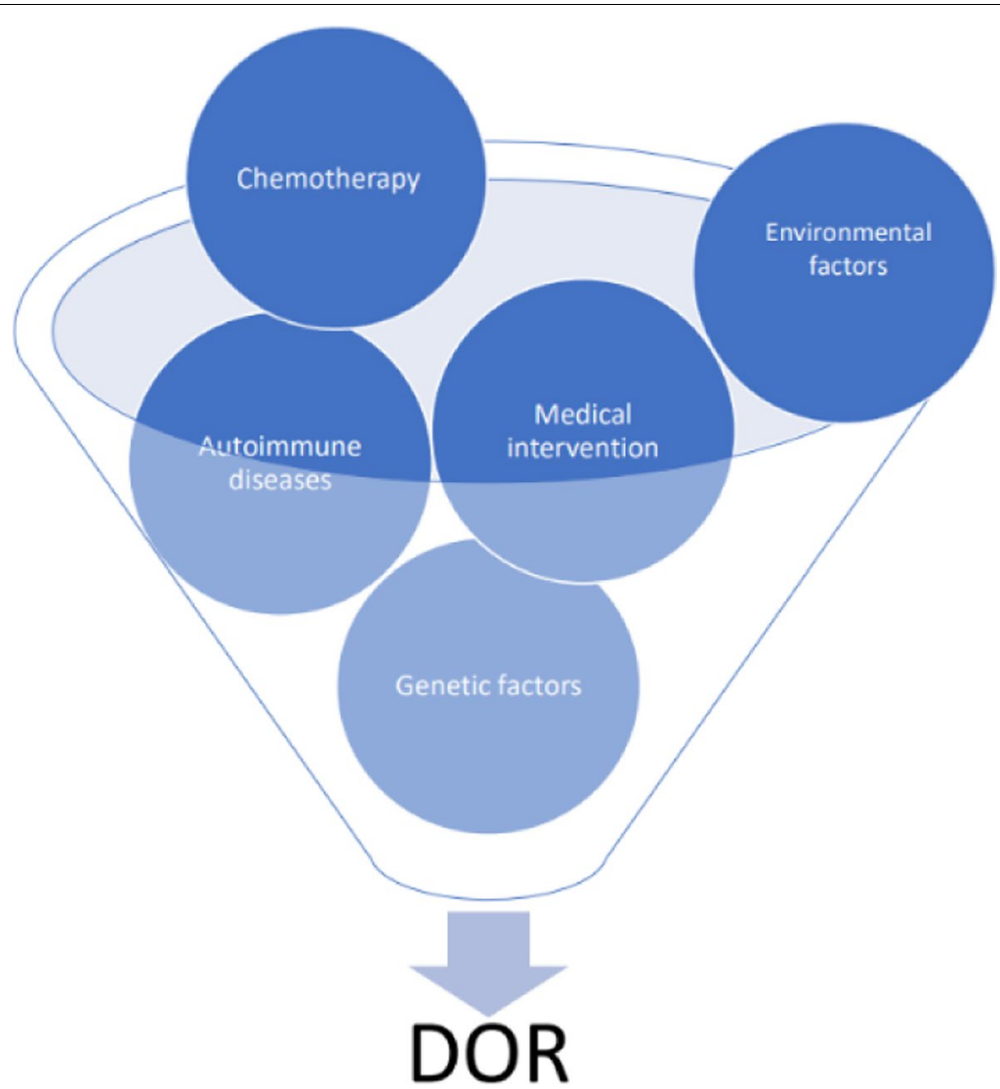

Fig. 1 Factors affecting the ovarian reserve, leading to diminishment of the ovarian reserve 
allelic forms of the FMR1 gene are identified according to the number of GGG repeats (Fig. 2): normal (<45 CGG); full mutation ( $>200 \mathrm{CGG}$ ), which influences complete gene suppression; premutation (55-200 CGG), which causes excessive synthesis of FMR1 in cells; intermediate mutant allele (45-55 CGG) [14]. The premutation allelic form manifests in two conditions: Fragile X-associated tremor/ataxia syndrome (FXTAS), associated with $\mathrm{X}$ chromosome suppression; and Fragile X-associated primary ovarian insufficiency (FXPOI) syndrome. The later was identified in 1990s and was a pilot study showing direct relationship between genetic pathological changes and low ovarian volume [15].

Approximately $20 \%$ of women with permutation have FXPOI and significant decline of ovarian reserve [12]. Studies show that the rate of permutation is 1:150-300 in the female population but it this constant varies significantly dependent on ethnicity, race, environmental and other factors [16, 17]. GGG repeats are normally interrupted by intermediate AGG repeats which are essential for stabilization of the genetic sequence. Abnormal interruption of GGG repeats has been shown to influence the formation of the ovarian reserve through impact on the FMR1 gene transcriptional activity [18]. As such, due to various mutations of the FMR1 gene, preimplantation diagnostic screening is recommended to identify permutation [19].

\section{Single-nucleotide polymorphisms (SNPs)}

Single-nucleotide polymorphisms are another form of genetic variability. They are caused by point mutations, so they exist in high abundance in human genome. They are found in genes coding the receptors of the Anti-Müllerian hormone - AMH (AMHR2), Follicle-stimulating hormone - FSH (FSHR), luteinizing hormone - LH
(LHCGR), estrogen (ESR), growth and differentiation factors (GDF9). They are also found in genes that are responsible for bone morphogenetic proteins - BMPs (gene TR53) [20, 21]. SNPs have been shown to play an important role in poor ovarian response (POR) and DOR development (Fig. 3). POR characterizes the response of the ovaries to hormonal stimulation and is directly related to DOR, but these concepts are distinguished. The concept of POR is used in reproductive medicine and includes an insufficient response of the ovaries to the introduction of large doses (more than $300 \mathrm{IU} /$ day) of gonadotropins, when in the stimulation regimens used in IVF programs it is not possible to ensure the growth and maturation of more than 3 follicles. In POR, the selection of oocytes and embryos is not based on an indicator of their quality, but only on the characteristics of viability, which reduces the effectiveness of treatment.

SNPs of FSH receptor are considered to be potential diagnostic genetic markers of POR [21], as FSH plays an crucial role in the formation of ovarian follicles, since after binding to the receptor, this hormone triggers many signaling reactions and other activating molecular mechanisms in cells. It is therefore regarded as a key marker of ovarian reserve status. The FSH receptor is a transmembrane protein in granulosa cells [22]. It's activation causes granulosa cell proliferation. It was shown that single-nucleotide polymorphisms in loci associated with FSH $(680,307,189)$, exon 10, are responsible for diminished ovarian reserve [22-24]. Due to the fact that FSH receptor plays a dominant role in the regulation of folliculogenesis, SNPs such as rs6165 and rs6166 are have been shown to correlate with changes in the ovarian reserve $[25,26]$. SNPs 29G $>$ A and 919G $>A$ in the FSH receptor are associated with $\mathrm{POR}$, by causing its inactivation and halting folliculogenesis [27]. AMH also has a
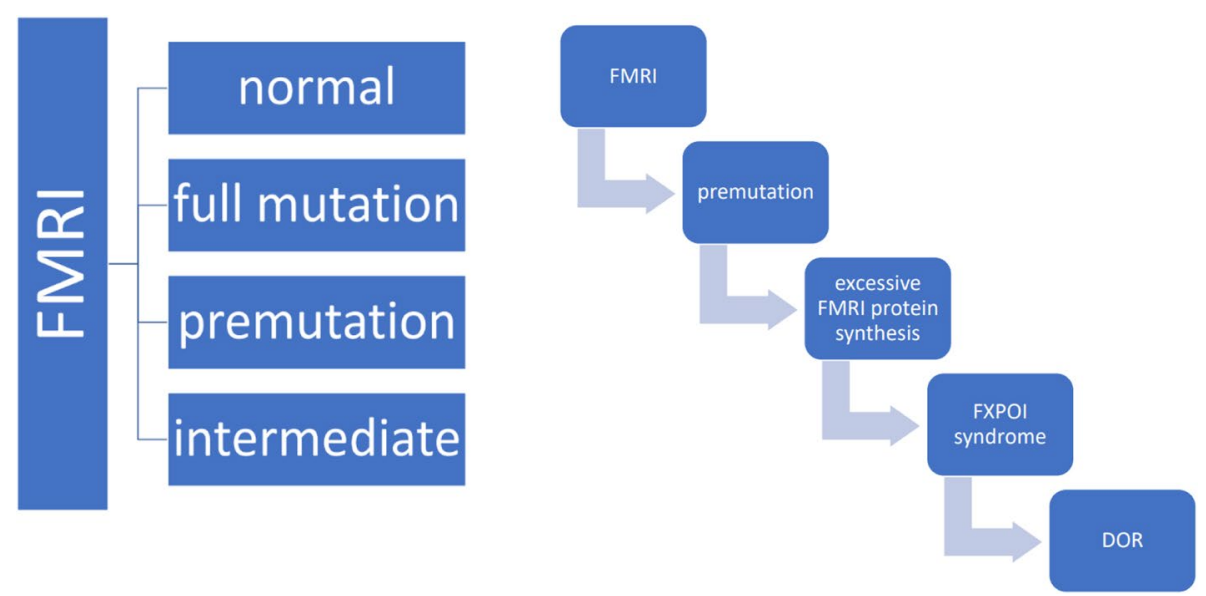

Fig. 2 Alleles of the FMRI gene and their role in DOR 


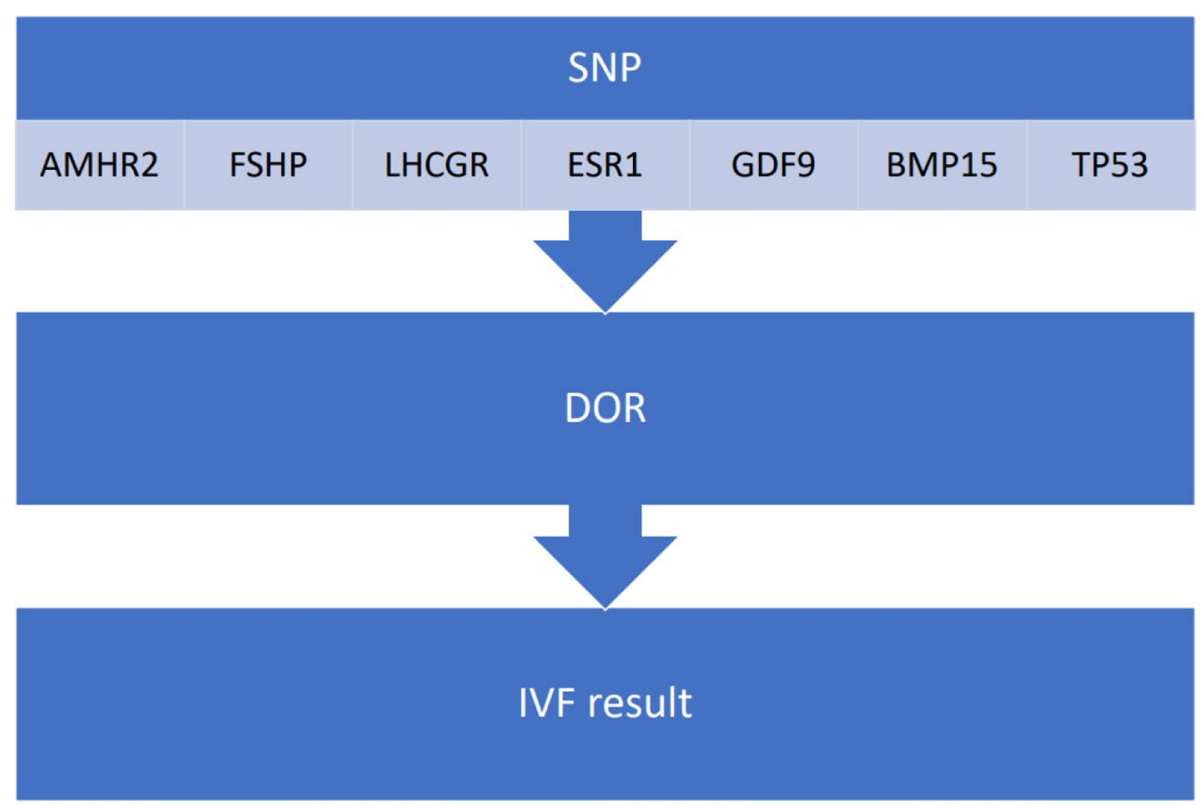

Fig. 3 The impact of SNPs on reproductive health

prominent role in folliculogenesis regulation and ovarian. AMH receptor SNPs polymorphisms, such as AMHRII$482 \mathrm{~A}>\mathrm{G}(23,24)$ have been shown to increase the risk of DOR [28-30]. LH, a key regulator of ovarian response to stimulus, is essential in regulation of the ovarian reserve. SNPs in the LH receptor, including rs4539842 (a set of six base pairs CTGCAG), rs12470652 (c.827A > G/p.Asn 291Ser), and rs2293275 (c.935G > A/p.Ser312Asn) impact the ovarian reserve and promote early POR [31, 32].

The ESR 1 gene is located in the $6^{\text {th }}$ chromosome and is responsible for coding the ESR protein, which plays an important role in regulating granulosa cell proliferation and folliculogenesis. SNPs of gene ESR1 have been shown to cause POR, but existing data is contradictive. Some research shows a direct correlation between ESR1 SNPs and POR [33], but other research indicates no obvious correlation [34]. This discrepancy may be due to the fact that POR is a multivariable condition, and ESR1 SNPs alone may not contribute entirely to POR.

Polymorphisms in genes GDF9, C398G, C447T, BMP15 have been shown to negatively impact ovarian response among females who are subject to controlled ovarian hyperstimulation. Existing data shows that GDF9 polymerphisms plays an important role in different stages of folliculogenesis [35]. GDF9 and BMP15 belong to a superfamily of transforming growth factors (beta) [36]. The SNPs of genes GDF9 and BMP15 have been identified: c.-9C $>\mathrm{G}$ (rs3810682), BMP15:c.328 + 905A > G (rs3897937), BMP15:c.852C > T (rs17003221); GDF9:c.134-694G >A (rs4705974),
GDF9:c.-31-951G > A (rs11748063), GDF9:c.-152G >C (rs30177), GDF9:g.1073C > T (rs803224) [36, 37]. These polymorphisms negatively influence folliculogenesis. The BMP15:c.852C > T SNP has been identified as a factor of DOR and ovarian reserve genetic marker [36]. Polymorphism of gene TR53 has also been shown to impact the state of the ovarian reserve and consequently the results of in vitro fertilization [38].

\section{Non-coding RNA molecules}

miRNA and piRNA have been shown to have an impact on granulosa cells with low ovarian volume because of RNA interference (RNAi) and various epigenetic rearrangements which determine genetic expression, making them an important target in genetic diagnostics and targeting in DOR [39].

The impact of miRNA-106a on the pathogenesis of DOR is actively studied. Its' action results in the lowering of the viability of granulosa cells and stimulate apoptosis through activation of apoptosis signal-regulating kinase 1 (ASK1) [40]. Additionally, miRNA-23a has been shown to participate in the development of folliculogenesis disorders and, as a result, DOR [41].

The decline of long non-coding RNA H19 (part of the conserved imprinted gene cluster that predetermines fetal stages of development) in the blood serum has been shown to be connected with the decline of AMH and an increased risk of extreme POR, therefore acting as a potential biomarker of POR and DOR [42]. Further studies are required to evaluate the full extent of non-coding 
miRNA role in ovarian role regulation, as existing data underlines their importance (Fig. 4).

\section{Genes involved in formation of primordial and pre-antral follicles}

Biallelic mutations of Folliculogenesis Specific BHLH Transcription Factor (FIGLA) gene (FIGLA) (specifically $2 \mathrm{~T}>$ Cp.Met1Thr), have been shown to cause a decline in the ovarian reserve [43]. The mentioned mutation does not determine gene transcription but blocks whole protein synthesis of FILGA which plays an important role in the formation of primordial follicles. Biallelic recessive mutations are connected to a loss of function of FIGLA, have been known to cause DOR [44]. Analysis of genome sequencing showed that mutations of ATG7 and ATG9A genes (connected with programmed cell death) cause reduced biosynthesis of autophagosomes (causing defects in autophagy, the mechanism regulating primary follicle differentiation) which may lead to DOR through folliculogenesis dysregulation [45]. Research showed the key role of Janus-kinase 1 (genetic profile $J A K 1$ ) in regulating activation of primary follicles and supporting the ovarian reserve. A range of integrated inner pathways, including JAK-STAT, have been shown to be responsible for regulation of the ovarian reserve, primary follicle growth and female fertility [46]. As such, disruption of JAK1 and it's pathways in associated genetic profiles is of interest in assessment of the ovarian reserve. Keratin gene mutations, resulting in it's pathology has been shown to affect ovarian health through immunohistochemical evaluation of $\mathrm{K} 8 / \mathrm{K} 18$ expression. Changes in $\mathrm{K} 8 / \mathrm{K} 18$ expression in the ovaries are associated with increased depletion of the ovarian reserve, which leads to primary ovarian insufficiency [47]. No specific genetic profiles have been studied in the case of Keratin structure and ovarian reserve health.

\section{Factors regulating gene expression and epigenetic changes}

Besides the previously mentioned factors, specific signaling proteins involved in metabolic regulation (sirtuins) have been shown to play a critical role in ovarian pathogenesis. Thus, a range of changes in sirtuin genetic profiles such as SIRT1, SIRT2, SIRT4, SIRT5, SIRT6, SIRT7, which regulate epigenetic gene silencing and suppress recombination of $\mathrm{rDNA}$, can lead to pathological changes in the ovaries. Accumulation of epimutations associated with sirtuin disfunction, age-related abundance of methylated regions in ovarian DNA have a considerable impact on their functions (Fig. 5) [48].

Interestingly, among women with low ovarian volume the influence of ADR- $\alpha 1,2$ and ADR- $\beta 2$ are predetermined by the depletion of gene expression and this has been shown to result in ovarian aging and DOR [49].

\section{Genes responsible for germ cell formation, meiosis, DNA repair}

Recent studies show that BRCA mutations cause a decline of the ovarian reserve and premature ovarian aging, accumulation of mutations in the DNA of female germ cells and primary follicle atresia. BRCA1/2 are responsible for homologous recombination of DNA and influence DNA repair (double-strand break - DSB), which are caused by ataxia-telangiectasia (AT). BRCA and AT DNA repair have been shown to play an important role the process of early onset ovarian dysfunction. $B R C A 1 / 2$ and AT-related DSB and DNA repair tend to weaken with age in different oocytes [50]. The number of primary follicles decreases and an increased accumulation of double-strand DNA breaks in oocytes is seen. Women with BRCA1/2 mutations have low ovarian volumes and early menopause [50]. Existing data hints that BRCA1/2 mutations may play an important role in ovarian reserve dysregulation.

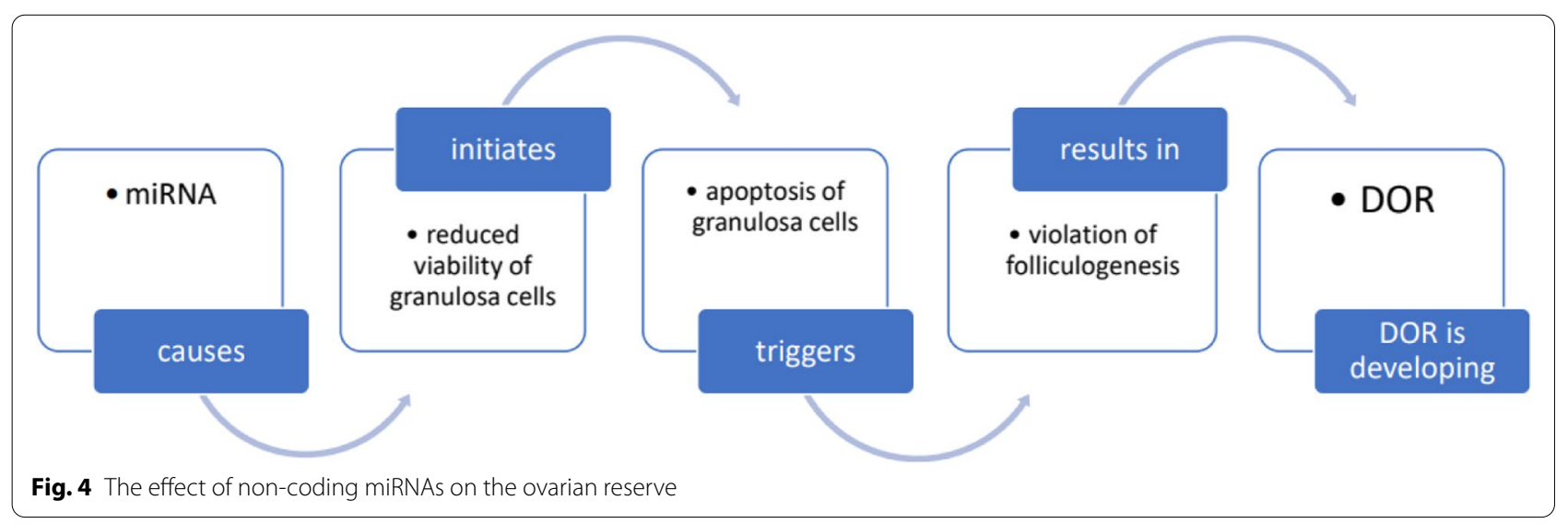


Epigenetic

profile of

granulosa

cells
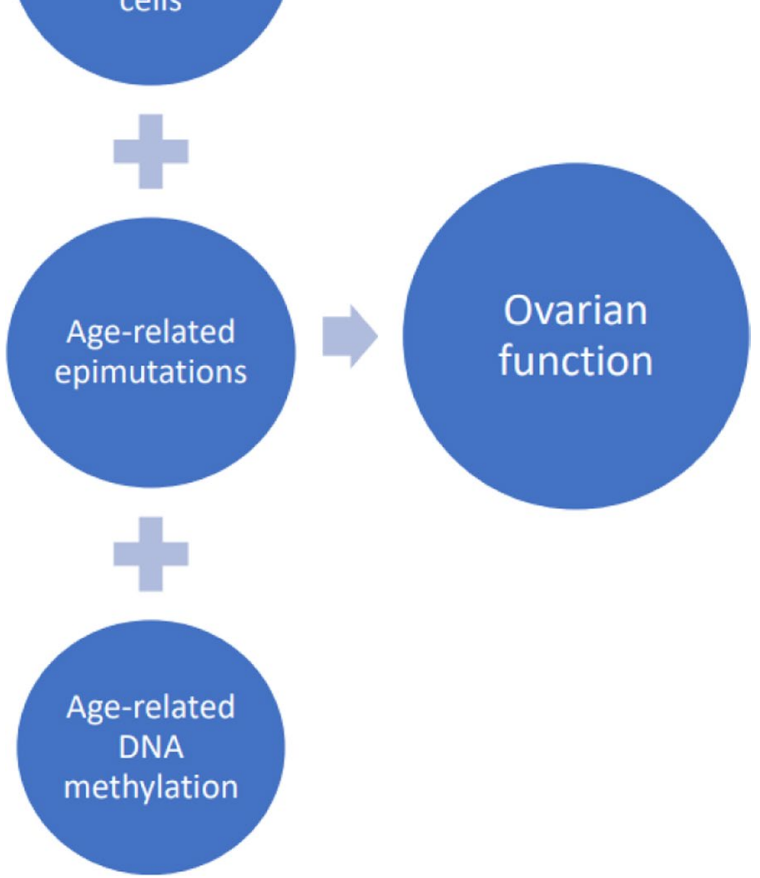

Fig. 5 Epigenetic factors that affect the functioning of the ovaries

Whole exome sequencing allowed to identify a new heterozygous missense mutation in the HFM-1 (human homologue of yeast Mer3) gene (HFM1). This pathological mutation is associated with DOR and causes defects of RNA splicing [51]. The defects of an alternative splicing are considered to be potential mechanisms which cause pathological decline of the ovarian reserve [51]. According to existing data, a heterozygous variation of KHDRBS1 is one of the reasons of such pathological changes. They appear in the form of delayed puberty and considerable depletion of secondary and pre-antral follicles. Thus, a more detailed examination of mutation will help to understand etiology, a molecular mechanism of pathological changes in the ovarian reserve $[52,53]$.

\section{Genes that have a somatic effect}

It is important to understand that the reviewed genes are not specific to the reproductive system, but also have a complex effect on the body, as most genetic profiles do. FMR1, SIRT, BRCA, BMP15, TP53, ADR, KHDPBS have varible expression profiles and therefore variable effects. For example, a premutation in the FMR1 gene is associated with Fragile X-associated tremor/ataxia syndrome
(FXTAS), which manifests itself as a progressive neurodegenerative disease with pronounced manifestations. tremor, ataxia, dementia, behavioral changes, and much more. Clinical manifestations include cerebellar ataxia, action tremor, parkinsonism, cognitive impairment, psychiatric disorders, peripheral neuropathy, and autonomic dysfunction of varying in severity, are possible. In women, due to the presence of a second $\mathrm{X}$ chromosome, this syndrome does not develop, however, it is known that carriers are more likely to suffer from depression and anxiety disorders. They also have an increased risk of developing primary ovarian failure [54]. This association is important to understand the varying profile of effect and expression on targeted genes. Additionally it is worth noting that mutations in the SIRT gene family, as well as other epigenetic disorders, have multiple aggravating consequences, including premature aging, neurodegenerative diseases, cancer, oxidative stress, and autophagy [55].

$B R C A$ genetic expression products are known regulators of cellular repair and lifecycle, maintaining the stability of the genome. BRCA1/2 mutations lead to disturbances in the mechanisms of molecular repair and cell division. Carriers have an increased risk of cancers of the breast, ovaries, fallopian tubes, peritoneum, prostate, pancreas, stomach, gallbladder and bile ducts, and melanoma. If the mutation is inherited from both parents, Fanconi anemia, malignant tumors and acute myeloid leukemia may develop [56].

Bone morphogenetic protein (BMP), a product of BMP gene cluster expression, is a growth factor and morphogenetic signaling protein family that is involved in structural organization of tissues. BMPs act on cells through specific BMP receptors (BMPRs) and play an important role in the development of the heart, central nervous system, and skeleton. Impaired BMR signaling can have pathologic effects on a developing embryo. Mutations in BMP and BMP inhibitors cause a number of diseases [57].

The p53 protein is an expression product of the TP53 gene, a transcription factor that regulates the cell cycle. p53 functions as a tumor suppressor and the TP53 gene is regarded as an anti-oncogene. Numerous studies have shown that imbalances in the expression of p53 isoforms and mutations in the TP53 gene cause such debilitating disorders as cancer, premature aging and degenerative diseases [58].

The $A D R$ cluster genes are involved in the regulation of lipid and carbohydrate metabolism, blood pressure, and heart function through expression products-adrenergic receptors. Mutations and polymorphisms of these genes can lead to the development of various diseases: arterial hypertension, heart disorders, ischemia, obesity, type I and II diabetes mellitus and insulin resistance $[59,60]$. 


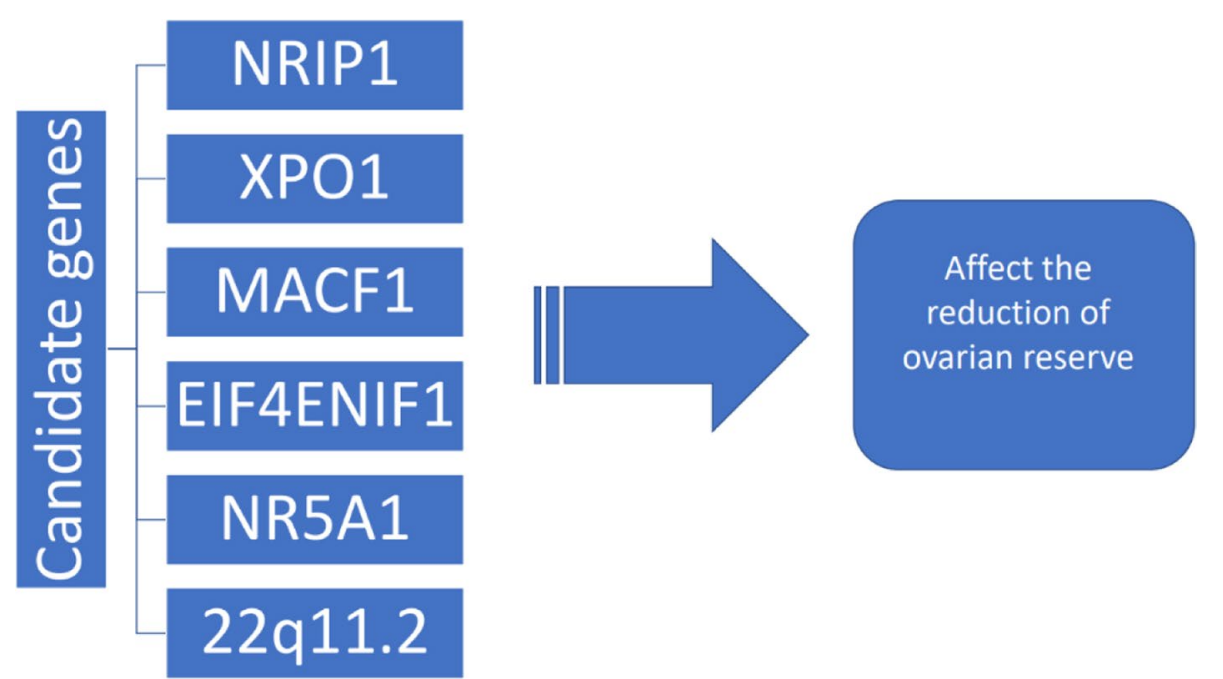

Fig. 6 New genes with a potential role in ovarian reserve pathology and homeostasis

The protein product of KHDPBS gene expression belongs to the STAR (signal transduction and activation of RNA) family and regulates the splicing of target genes, which plays an important role in the formation of contacts and myelination in the nervous system. STAR products are also involved in the embryonic development of the nervous system. Disorders of $K H D P B S$ genes are associated with diseases such as schizophrenia and autism, as well as with other neurodegenerative pathologies [61].

\section{New findings on genes}

Recent studies have identified new candidate genes which may be involved in ovarian pathogenesis (Fig. 6). These include NRIP1, XPO1 and MACF1, which have been shown to be related to ovarian functioning, but their role in the human body is not fully understood [62]. A new gene mutation EIF4ENIF1 has been discovered recently, and is identified in patients with low ovarian volume, prompting investigation and increased interest to the role of genetic factors in ovarian homeostasis [63]. New variations of gene NR5A1 have been shown to influence the decline of the ovarian reserve, causing primary ovarian insufficiency, which can cause primary ovarian insufficiency (POI) and infertility [64]. Besides, 22q11.2 changes are identified among women with low ovarian volume and POI [65].

\section{Conclusions}

Genetic factors should be taken into account in the treatment and diagnosis of ovarian reserve pathology. Identifying genetic predisposition to early ovarian reserve depletion may serve beneficial in family planning. Existing data show an abundant amount of research on genetic and epigenetic profiles which may influence ovarian reserve formation and consistency. More so, several specific genetic markers have been identified to be associated with ovarian reserve depletion through several important pathological pathways. Further research is needed to evaluate the unsupported conclusions and unproven correlations between genetic mutations and ovarian reserve stability. Inconsistent data shows that the ovarian reserve is subjected to a multifactorial influence, and disruption of separate factors may not consistently lead to ovarian reserve pathology.

\section{Acknowledgements \\ None.}

\section{Authors' contributions}

Aleksandra V. Moiseeva: supervision, conceptualization, resources, validation, writing - original draft. Varvara A. Kudryavtseva:, data curation, methodology, validation, resources, writing - original draft. Vladimir N. Nikolenko: methodology, data curation, investigation, writing - original draft. Marine M. Gevorgyan: resources, validation, writing - original draft. Ara L. Unanyan:: resources, conceptualization, supervision, methodology, writing - review \& editing. Anastassia A. Bakhmet: writing - review \& editing, methodology, visualization. Mikhail Y. Sinelnikov: writing - original draft, writing - review \& editing, methodology, formal analysis, validation. The authors read and approved the final manuscript.

\section{Funding \\ None.}

\section{Availability of data and materials}

All data and materials are available from the corresponding author upon reasonable request. 


\section{Declarations}

Ethics approval and consent to participate

Not applicable.

\section{Consent for publication}

Not applicable.

\section{Competing interests}

The authors declare no competing interests.

\section{Author details}

${ }^{1}$ Sechenov University, Mohovaya 11c10, Moscow, Russian Federation. ${ }^{2}$ Moscow State University, Moscow, Russian Federation. ${ }^{3}$ Saratov State Medical University, Moscow, Russian Federation. ${ }^{4}$ Research Institute of Human Morphology, Moscow, Russian Federation.

\section{Received: 2 June 2021 Accepted: 23 July 2021}

Published online: 06 August 2021

\section{References}

1. Mikhaleva LM, et al. Malignant transformation and associated biomarkers of ovarian endometriosis: a narrative review. Adv Ther. 2020;37:2580-603.

2. Tang $\mathrm{R}, \mathrm{Yu} \mathrm{Q}$. Novel variants in women with premature ovarian function decline identified via whole-exome sequencing. J Assist Reprod Genet. 2020;37:2487-502.

3. Urakova NA, Urakov AL, Nikolenko VN, Lovtsova LV. Application of Infrared Monitoring for Personalization of Obstetric Aid. Sovremenniye Tehnologii V Med. 2019;11(4). In Russian.

4. Nesbit CB, et al. New perspectives on the genetic causes of diminished ovarian reserve and opportunities for genetic screening: systematic review and meta-analysis. FS Rev. 2020;1:1-15.

5. Greene AD, Patounakis G, Segars JH. Genetic associations with diminished ovarian reserve: a systematic review of the literature. J Assist Reprod Genet. 2014;31:935-46.

6. Devine K, et al. Diminished ovarian reserve in the United States assisted reproductive technology population: diagnostic trends among 181,536 cycles from the society for assisted reproductive technology clinic outcomes reporting system. Fertil Steril. 2015;104:612-619.e3.

7. Hikolenko BH, et al. Tubal health: medico-social and psycho-logical aspects of the problem. Nurs Gynecol. 2020. https://doi.org/10.18565/aig. 2020.II.213-224

8. Di Paola R, et al. Are we choosing the correct FSH starting dose during controlled ovarian stimulation for intrauterine insemination cycles? Potential application of a nomogram based on woman's age and markers of ovarian reserve. Arch Gynecol Obstet. 2018;298:1029-35.

9. Burnik Papler T, et al. PGR and PTX3 gene expression in cumulus cells from obese and normal weighting women after administration of longacting recombinant follicle-stimulating hormone for controlled ovarian stimulation. Arch Gynecol Obstet. 2019;299:863-71.

10. Šalamun V, Verdenik I, Laganà AS, Vrtačnik-Bokal E. Should we consider integrated approach for endometriosis-associated infertility as gold standard management? Rationale and results from a large cohort analysis. Arch Gynecol Obstet. 2018;297:613-21.

11. Facchinetti F, et al. Breakthroughs in the Use of Inositols for Assisted Reproductive Treatment (ART). Trends Endocrinol Metab TEM. 2020;31:570-9.

12. Batiha $\mathrm{O}$, et al. A study on the role of FMR1 CGG trinucleotide repeats in Jordanian poor ovarian responders. Gene. 2021:767:145174.

13. Rehnitz J, et al. FMR1 expression in human granulosa cells increases with exon 1 CGG repeat length depending on ovarian reserve. Reprod Biol Endocrinol RBE. 2018;16:65.

14. Noto V, Harrity C, Walsh D, Marron K. The impact of FMR1 gene mutations on human reproduction and development: a systematic review. J Assist Reprod Genet. 2016;33:1135-47.

15. Conway G, Hettiarachchi S, Murray A, Jacobs P. Fragile X premutations in familial premature ovarian failure. Lancet. 1995;346:309-10.
16. Seltzer MM, et al. Prevalence of CGG expansions of the FMR1 gene in a US population-based sample. Am J Med Genet. 2012;159:589-97.

17. Pastore LM, et al. Distribution of the FMR1 gene in females by race/ ethnicity: women with diminished ovarian reserve versus women with normal fertility (SWAN study). Fertil Steril. 2017;107:205-211.e1.

18. Lekovich J, et al. CGG repeat length and AGG interruptions as indicators of fragile $X$-associated diminished ovarian reserve. Genet Med. 2018;20:957-64.

19. Sullivan-Pyke C, Dokras A. Preimplantation genetic screening and preimplantation genetic diagnosis. Obstet Gynecol Clin North Am. 2018;45:113-25.

20. Karki R, Pandya D, Elston RC, Ferlini C. Defining, "mutation" and "polymorphism" in the era of personal genomics. BMC Med Genomics. 2015;8:37.

21. Tănase A-E, et al. Follicle-stimulating hormone receptor gene polymorphisms of ovarian reserve markers in Romanian population. Exp Ther Med. 2020;20:203.

22. Riccetti $\mathrm{L}$, et al. Genetics of gonadotropins and their receptors as markers of ovarian reserve and response in controlled ovarian stimulation. Best Pract Res Clin Obstet Gynaecol. 2017;44:15-25.

23. Desai SS, et al. Association of allelic combinations of FSHR gene polymorphisms with ovarian response. Reprod Biomed Online. 2013;27:400-6.

24. Song D, et al. Sequence variants in FSHR and CYP19A1 genes and the ovarian response to controlled ovarian stimulation. Fertil Steril. 2019;112:749-757.e2.

25. Čuš M, Vlaisavljević V, Repnik K, Potočnik U, Kovačič B. Could polymorphisms of some hormonal receptor genes, involved in folliculogenesis help in predicting patient response to controlled ovarian stimulation? J Assist Reprod Genet. 2019;36:47-55.

26. Pabalan N. et al. Evaluating influence of the genotypes in the folliclestimulating hormone receptor (FSHR) Ser680Asn (rs6166) polymorphism on poor and hyper-responders to ovarian stimulation: a meta-analysis. J Ovarian Res. 2014;7:1-11

27. Ghezelayagh $Z$, et al. The impact of genetic variation and gene expression level of the follicle-stimulating hormone receptor on ovarian reserve. Cell J. 2018;19:620-6.

28. Motawi TMK, et al. The role of gene polymorphisms and AMH level in prediction of poor ovarian response in Egyptian women undergoing IVF procedure. J Assist Reprod Genet. 2017:34:1659-66.

29. Papanikolaou IG, et al. Combined study on the single nucleotide polymorphisms in the follicle-stimulating hormone receptor (Ser680Asn) and anti-Müllerian hormone receptor type II (-482A>G) as genetic markers in assisted reproduction. Horm. Mol. Biol. Clin. Investig. 2019:38:1-9.

30. Umer $\mathrm{S}$, et al. Regulation of AMH, AMHR-II, and BMPs $(2,6)$ Genes of bovine granulosa cells treated with exogenous FSH and their association with protein hormones. Genes 2019;10:1038.

31. Javadi-Arjmand $M$, et al. Evaluation of the prevalence of Exons 1 and 10 polymorphisms of LHCGR gene and its relationship with IVF success. Reprod Infertil. 2019;20:218-24.

32. Regan SLP, et al. Infertility and ovarian follicle reserve depletion are associated with dysregulation of the FSH and $\mathrm{LH}$ receptor density in human antral follicles. Mol Cell Endocrinol. 2017:446:40-51.

33. de Mattos CS, et al. ESR1 and ESR2 gene polymorphisms are associated with human reproduction outcomes in Brazilian women. J Ovarian Res. 2014;7:114

34. Li J, et al. Lack of association between ESR1 gene polymorphisms and premature ovarian failure in Serbian women. Climacteric. 2014;17:247-51.

35. Bilibio JP, et al. GDF9 polymorphisms: influence on ovarian response in women undergoing controlled ovarian hyperstimulation. JBRA Assist Reprod. 2020;24:447-53.

36. Santos M, et al. Association of BMP15 and GDF9 variants to premature ovarian insufficiency. J Assist Reprod Genet. 2019;36:2163-9.

37. Belli M, Shimasaki S. Molecular aspects and clinical relevance of GDF9 and BMP15 in ovarian function. Vitam Horm. 2018;107:317-48.

38. Oliveira JBA, et al. The TP53 gene ( $\mathrm{rs} 1625895) \mathrm{C}>$ T polymorphism is associated with ovarian reserve and ovarian response to recombinant FSH during IVF/ICSI treatment. Fertil Steril. 2019:112:e17-8.

39. Chen $D$, et al. Altered microRNA and Piwi-interacting RNA profiles in cumulus cells from patients with diminished ovarian reserve. Biol Reprod. 2017;97:91-103. 
40. Hong $L$, et al. miR-106a increases granulosa cell viability and is downregulated in women with diminished ovarian reserve. J Clin Endocrinol Metab. 2018;103:2157-66.

41. Luo H, Han Y, Liu J, Zhang Y. Identification of microRNAs in granulosa cells from patients with different levels of ovarian reserve function and the potential regulatory function of miR-23a in granulosa cell apoptosis. Gene. 2019;686:250-60.

42. Xia X, Burn MS, Chen Y, Karakaya C, Kallen A. The relationship between $\mathrm{H} 19$ and parameters of ovarian reserve. Reprod Biol Endocrinol RBE. 2020;18:46.

43. Chen B, et al. Consanguineous familial study revealed biallelic FIGLA mutation associated with premature ovarian insufficiency. J Ovarian Res. 2018:11:48.

44. Yuan $\mathrm{P}$, et al. Bi-allelic recessive loss-of-function mutations in FIGLA cause premature ovarian insufficiency with short stature. Clin Genet. 2019:95:409-14.

45. Delcour C, et al. ATG7 and ATG9A loss-of-function variants trigger autophagy impairment and ovarian failure. Genet Med Off J Am Coll Med Genet. 2019;21:930-8.

46. Sutherland JM, et al. Janus kinase JAK1 maintains the ovarian reserve of primordial follicles in the mouse ovary. Mol Hum Reprod. 2018;24:533-42.

47. Gaytan F, Morales C, Roa J, Tena-Sempere M. Changes in keratin 8/18 expression in human granulosa cell lineage are associated to cell death/ survival events: potential implications for the maintenance of the ovarian reserve. Hum Reprod Oxf Engl. 2018;33:680-9.

48. Olsen $\mathrm{KW}$, et al. A distinctive epigenetic ageing profile in human granulosa cells. Hum Reprod Oxf Engl. 2020;35:1332-45.

49. Zangeneh FZ, Bagheri M, Shoushtari MS, Naghizadeh MM. Expression of ADR-a 1, 2 and ADR- $\beta 2$ in cumulus cell culture of infertile women with polycystic ovary syndrome and poor responder who are a candidate for IVF: the novel strategic role of clonidine in this expression. J Recept Signal Transduct. 2020;0:1-10.

50. Turan V, Oktay K. BRCA-related ATM-mediated DNA double-strand break repair and ovarian aging. Hum Reprod Update. 2020;26:43-57.

51. Zhe J, et al. A novel heterozygous splice-altering mutation in HFM1 may be a cause of premature ovarian insufficiency. J Ovarian Res. 2019;12:61.

52. Wang B, et al. Sequence variants of KHDRBS1 as high penetrance susceptibility risks for primary ovarian insufficiency by mis-regulating mRNA alternative splicing. Hum Reprod Oxf Engl. 2017;32:2138-46.

53. Begum $\mathrm{K}$, et al. Ethnicity or environment: effects of migration on ovarian reserve among Bangladeshi women in the United Kingdom. Fertil Steril. 2016:105:744-754.e1.
54. Cabal-Herrera AM, Tassanakijpanich N, Salcedo-Arellano MJ, Hagerman RJ. Fragile X-Associated Tremor/Ataxia Syndrome (FXTAS): pathophysiology and clinical implications. Int J Mol Sci. 2020;21:744-754.e1.

55. Wang Y, Yang J, Hong T, Chen X, Cui L. SIRT2: Controversy and multiple roles in disease and physiology. Ageing Res Rev. 2019;55:100961.

56. Ibrahim M, Yadav S, Ogunleye F, Zakalik D. Male BRCA mutation carriers: clinical characteristics and cancer spectrum. BMC Cancer. 2018;18:179.

57. Lowery JW, Rosen V. The BMP Pathway and Its Inhibitors in the Skeleton. Physiol Rev. 2018;98:2431-52

58. Giacomelli AO, et al. Mutational processes shape the landscape of TP53 mutations in human cancer. Nat Genet. 2018;50:1381-7.

59. Zangeneh FZ, Bagheri M, Shoushtari MS, Naghizadeh MM. Expression of ADR-a1, 2 and ADR- $\beta 2$ in cumulus cell culture of infertile women with polycystic ovary syndrome and poor responder who are a candidate for IVF: the novel strategic role of clonidine in this expression. J Recept Signal Transduct Res. 2021;41:263-72.

60. Wu M-H, et al. Obesity exacerbates rat cerebral ischemic injury through enhancing ischemic Adiponectin-containing neuronal apoptosis. Mol Neurobiol. 2016;53:3702-13.

61. Ehrmann I, Fort P, Elliott DJ. STARs in the CNS. Biochem Soc Trans. 2016;44:1066-72

62. Jaillard S, et al. New insights into the genetic basis of premature ovarian insufficiency: Novel causative variants and candidate genes revealed by genomic sequencing. Maturitas. 2020;141:9-19.

63. Zhao M, Feng F, Chu C, Yue W, Li L. A novel ElF4ENIF1 mutation associated with a diminished ovarian reserve and premature ovarian insufficiency identified by whole-exome sequencing. J Ovarian Res. 2019;12:119.

64. Jaillard S, et al. Analysis of NR5A1 in 142 patients with premature ovarian insufficiency, diminished ovarian reserve, or unexplained infertility. Maturitas. 2020;131:78-86.

65. Jaillard $\mathrm{S}$, et al. 22q11.2 rearrangements found in women with low ovarian reserve and premature ovarian insufficiency. J Hum Genet. 2018;63:691-8

\section{Publisher's Note}

Springer Nature remains neutral with regard to jurisdictional claims in published maps and institutional affiliations.
Ready to submit your research? Choose BMC and benefit from:

- fast, convenient online submission

- thorough peer review by experienced researchers in your field

- rapid publication on acceptance

- support for research data, including large and complex data types

- gold Open Access which fosters wider collaboration and increased citations

- maximum visibility for your research: over $100 \mathrm{M}$ website views per year

At BMC, research is always in progress.

Learn more biomedcentral.com/submissions 